\title{
Identification of neural circuits underlying P300 abnormalities in schizophrenia
}

\author{
BRIAN F. O'DONNELL, ${ }^{\mathrm{a}, \mathrm{g}}$ ROBERT W. McCARLEY, ${ }^{\mathrm{a}, \mathrm{b}}$ GEOFFREY F. POTTS, \\ DEAN F. SALISBURY, ${ }^{\mathrm{a}, \mathrm{b}}$ PAUL G. NESTOR, ${ }^{\mathrm{a}, \mathrm{c}}$ YOSHIO HIRAYASU, ${ }^{\mathrm{a}}$ \\ MARGARET A. NIZNIKIEWICZ, ${ }^{\mathrm{a}}$ JOHN BARNARD, ${ }^{\mathrm{d}}$ ZI JEN SHEN, ${ }^{\mathrm{d}}$ \\ DAVID M. WEINSTEIN, ${ }^{\mathrm{e}}$ FRED L. BOOKSTEIN, ${ }^{\mathrm{f}}$ AND MARTHA E. SHENTON ${ }^{\mathrm{a}, \mathrm{b}}$ \\ ${ }^{a}$ Department of Psychiatry, Harvard Medical School and Brockton VA Medical Center, Brockton, MA, USA \\ ${ }^{b}$ McLean Hospital Cognitive Neuroscience Laboratory, Belmont, MA, USA \\ ${ }^{\mathrm{c}}$ Department of Psychology, University of Massachusetts, Boston, USA \\ d Department of Statistics, Harvard University, Cambridge, MA, USA \\ e Department of Computer Science, University of Utah, Salt Lake City, USA \\ ${ }^{\mathrm{f}}$ Institute of Gerontology, University of Michigan, Ann Arbor, USA \\ ${ }^{\mathrm{g}}$ Department of Psychology, University of Indiana, Bloomington, USA
}

\begin{abstract}
Event-related potentials (ERPs) provide a noninvasive method to evaluate neural activation and cognitive processes in schizophrenia. The pathophysiological significance of these findings would be greatly enhanced if scalp-recorded ERP abnormalities could be related to specific neural circuits and/or regions of the brain. Using quantitative approaches in which scalp-recorded ERP components are correlated with underlying neuroanatomy in schizophrenia, we focused on biophysical and statistical procedures (partial least squares) to relate the auditory P300 component to anatomic measures obtained from quantitative magnetic resonance imaging. These findings are consistent with other evidence that temporal lobe structures contribute to the generation of the scalp-recorded P300 component and that P300 amplitude asymmetry over temporal recording sites on the scalp may reflect anatomic asymmetries in the volume of the superior temporal gyrus in schizophrenia.
\end{abstract}

Descriptors: Event-related potentials, P300, MRI, Neuroanatomy, Schizophrenia

Event-related potential (ERP) techniques have been used in the study of schizophrenia for several decades, but determining the relationship of ERP abnormalities to specific anatomic abnormalities has only recently been undertaken. Here, we survey methods for establishing the relationship of scalp-recorded ERPs and neuroanatomy, focusing on the auditory P300 component. We first review P300 amplitude and topography disturbances in schizophrenia and evidence from a variety of techniques which have indicated an association of the P300 component with temporal lobe structures. We next review biophysical source analysis approaches, with a demonstration of bioelectric modeling of the P300 component on

This work was supported by grants from NIMH (no. 40799 to R.W.M.), the Department of Veterans Affairs Schizophrenia Center (to R.W.M.), the Commonwealth of Massachusetts Research Center (to R.W.M.), and the National Alliance for Research on Schizophrenia and Depression (to B.F.O., D.F.S., M.G.N., R.W.M.) and by NIMH Research Scientist Development Award KO1-MH00746-04 (to M.E.S.), NIMH First Award (to M.E.S.), and a grant from the Stanley Foundation (to M.E.S.).

Address reprint requests to: R. W. McCarley, Psychiatry (116A), Brockton VA Medical Center, 940 Belmont Street, Brockton, MA 02401, E-mail: mccarley@warren.med.harvard.edu; or B. F. O'Donnell, Department of Psychology, University of Indiana, Bloomington, IN 47405, E-mail: bodonnel@indiana.edu. The SPSS code for the PLS procedure described in this paper is available from the corresponding authors. an individual head and brain. We conclude with an application of a recently developed multivariate statistical technique, partial least squares analysis. This technique can be applied to define the relationships among large numbers of structural and electrophysiological measures in the relatively small sample size typical in brain imaging studies. In the example presented here, partial least squares analysis was used to relate volumetric measures of temporal lobe gray matter structures to the P300 and N200 components recorded over a 10-20 montage.

\section{P300 Component in Schizophrenia}

Schizophrenia is a severe behavioral disorder, often associated with hallucinations, delusions, and alterations in emotional response. Onset is often abrupt, usually occurring in early adulthood. The course of the illness is heterogeneous, ranging from complete recovery to a lifelong incapacity and inability to engage in normal social or occupational activity. At the end of the 19th century, investigators speculated that damage or destruction of cells in the cerebral cortex must be associated with the devastating behavioral abnormalities and cognitive deficits of schizophrenia (Kraepelin, 1919/1971). Evidence of structural damage to the brain, however, proved to be elusive, with persuasive findings only emerging in the 1980s (Benes \& Bird, 1987; Kovelman \& Scheibel, 1984; McCar- 
ley, Hsiao, Freedman, Pfefferbaum, \& Donchin, 1996; McCarley et al., in press; Shenton, Wible, \& McCarley, 1997; Wible, Shenton, \& McCarley, 1997).

Some recent models of the pathophysiology of schizophrenia posit a disturbance of neuromodulation and synaptic connectivity, partially manifesting in brain development and partially later in time (Benes, 1995; McCarley et al., 1996; Olney \& Farber, 1995). If schizophrenia entails a component with a disorder of neural circuits, then the measurement of electrical currents produced by activity in these circuits should provide an important method to investigate the disorder. In particular, electrical activity reflecting attention, working memory, and categorization, faculties frequently disrupted in the illness, would be expected to be abnormal (Bleuler, 1911/1950; Chapman \& Chapman, 1973; Neale \& Oltmanns, 1980; Nestor \& O’Donnell, 1997).
Application of ERP paradigms to schizophrenia has revealed marked abnormalities (Levit, Sutton, \& Zubin, 1973; Roth, Pfefferbaum, Horvath, Berger, \& Kopell, 1980). In the initial period of investigation, the P300 component of the ERP recorded at midline electrode sites was most intensively studied (Figure 1). Here, we use P300 to refer to the P3b component elicited by target stimuli typically in an oddball paradigm. The P3a to novel nontarget task stimuli has been investigated in cases of schizophrenia but appears to index different neural systems (Grillon, Ameli, \& Glazer, 1991; Grillon, Courchesne, Ameli, Geyer, \& Braff, 1990; O’Donnell et al., 1996). Reduction of P300 amplitude to target stimuli has been found across laboratories (reviewed by Bruder et al., 1996; McCarley, Faux, Shenton, Nestor, \& Adams, 1991), although more reliably for auditory than visual stimuli (Ford et al., 1994a). Although auditory P300 latency prolongation sometimes has been

\section{FREQUENT}
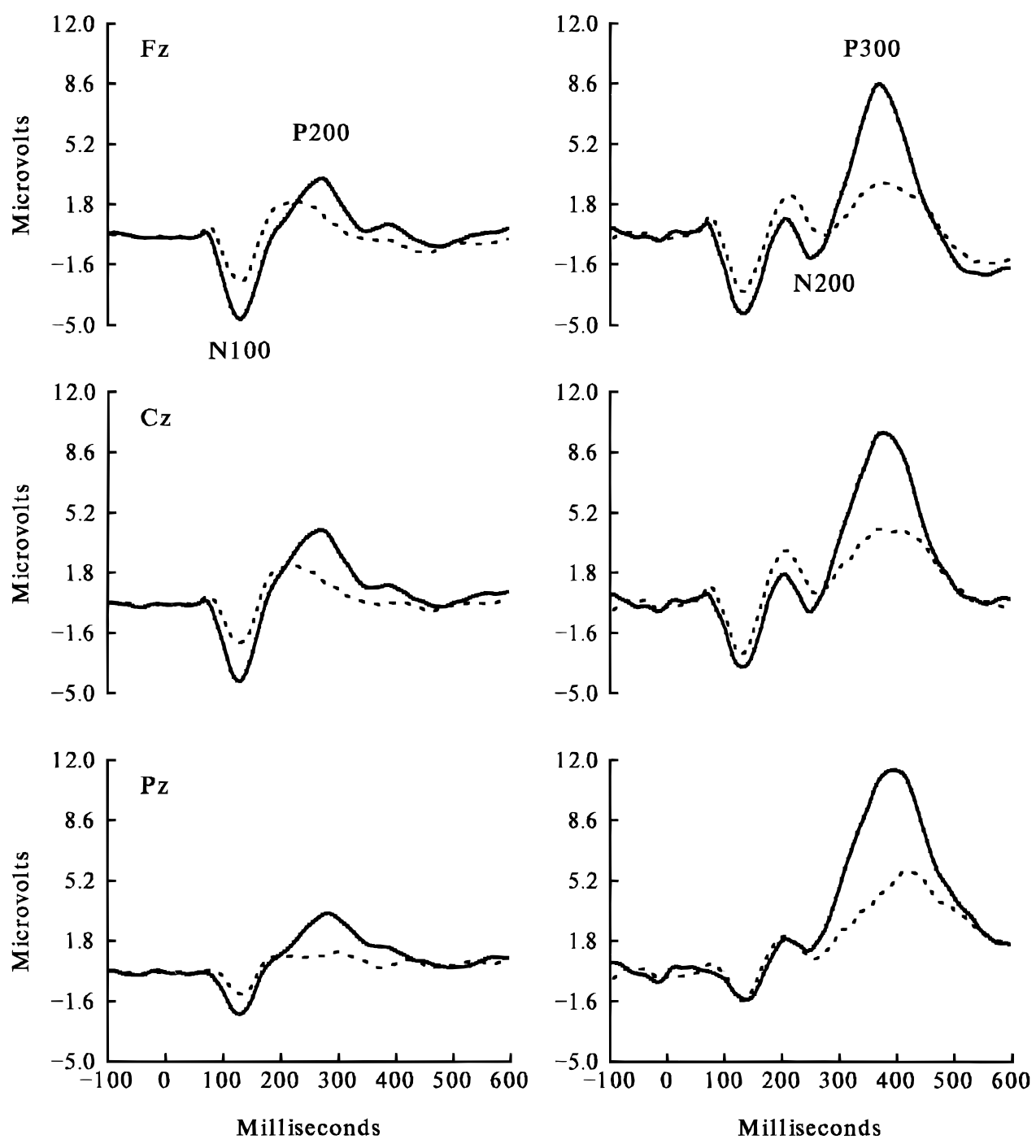

Control

Schizophrenic

Figure 1. Grand average ERPs from normal subjects and age-, gender-, and handedness-matched patients with schizophrenia, showing marked P300 amplitude reduction to target tones at midline sites. 
reported in schizophrenia, $\mathrm{P} 300$ amplitude reduction is not due to increased latency variability in the patients (Ford, White, Lim, \& Pfefferbaum, 1994b; Roth et al., 1980). Auditory P300 amplitude reduction has been shown in patients receiving medication (Faux et al., 1990; Pfefferbaum, Ford, White, \& Roth, 1989), patients withdrawn from medication (Faux et al., 1993; Ford et al., 1994a; Pfefferbaum et al., 1989), and patients in the first episode of the illness (Salisbury et al., 1998) and in never-medicated patients (Hirayasu et al., 1998). Consequently, auditory P300 amplitude reduction may represent an enduring biological feature of schizophrenia that is relatively insensitive to clinical status or medication after the onset of the illness. However, midline P300 amplitude reduction has been found in other psychiatric disorders, such as depression and alcoholism (Blackwood et al., 1987; Bruder et al., 1996; Patterson, Williams, McLean, Smith, \& Scaeffer, 1987; Pfefferbaum, Ford, White, \& Mathalon, 1991; Pfefferbaum, Wenegrat, Ford, Roth, \& Kopell, 1984; Roth, Duncan, Pfefferbaum, \& TimsitBerthier, 1986), indicating that midline amplitude reduction alone is not specific to schizophrenia.

Although auditory P300 amplitude reduction is not specific to schizophrenia with respect to other psychotic disorders, it is possible that the topographic distribution of the P300 reduction might be specific to schizophrenia. Our initial use of topographic analysis demonstrated that schizophrenic patients show a greater P300 amplitude reduction over the left than over the right temporal lobe regions (Morstyn, Duffy, \& McCarley, 1983; Figure 2). Subsequent studies (McCarley et al., 1997) have shown that the lateralized P300 deficit appears in off-medication schizophrenic patients (Faux et al., 1993), in first-episode schizophrenic patients (Salisbury et al., 1998), and in never-medicated schizotypal subjects (Salisbury, Voglmaier, Seidman, \& McCarley, 1996), when a nose reference (Faux et al., 1990) and a 64-channel recording (Potts, Hirayasu, O’Donnell, Shenton, \& McCarley, 1998) is used. The left $<$ right P300 asymmetry has been replicated by many investigators using similar paradigms (e.g., Bolsche, Mac-
Crimmon, \& Kropf, 1996; Bruder et al., 1996; Ford and Sidman, 1988; Gerez and Tello, 1995; Kraft, Schwartzskopf, Torello, Olsen, \& Nasrallah, 1991; Muir, St. Clair, \& Blackwood, 1991; Scherg \& Berg, 1996; Sieg, Willsie, Preston, \& Gaffney, 1991; Souza et al., 1995; Strik, Dierks, Franzek, Stober, \& Maurer, 1994a, 1994b; Turetsky, Colbath, Erwin, \& Gur, 1998; Weisbrod et al., 1997). Bruder et al. (1996) noted that in most studies in which the asymmetry was not replicated, the design incorporated a button-press response (e.g., Ford et al., 1994a; Pfefferbaum et al., 1989). Increased task difficulty may also reduce P300 asymmetry (Salisbury et al., 1994; Weisbrod et al., 1997).

In a study comparing first-episode schizophrenic patients, firstepisode affective psychotic patients, and age matched controls, Salisbury et al. (1998) found that first-episode schizophrenic patients displayed smaller P300 amplitude over the left temporal region (T3) than did either first-episode affective patients or normal control subjects. The first psychotic episode affective disorder patients, although showing an overall P300 amplitude reduction, did not show a left $<$ right asymmetry (see Figure 2 ). These data suggest that P300 left temporal region abnormalities reported in chronic schizophrenia are present at the onset of the illness and may be specific to schizophrenic psychosis relative to affective psychosis.

The pathophysiological significance of these ERP findings would be greatly increased if they could be associated with specific neural structures or circuits in humans. Several approaches have been used to attack this problem. We first review studies using depth recordings and lesions to identify regions that might contribute to the scalp-recorded P300 component. We then report ongoing work using two different approaches that integrate information derived from topographic recording of electrical activity with information obtained from quantitative structural magnetic resonance imaging (MRI). The first approach incorporates biophysical techniques to estimate the relationship of electrical activity recorded on the surface of the scalp to the underlying cortical surface. The second

\section{First Psychotic Episode Study Integrated scalp topography $(300-400 \mathrm{msec})$}

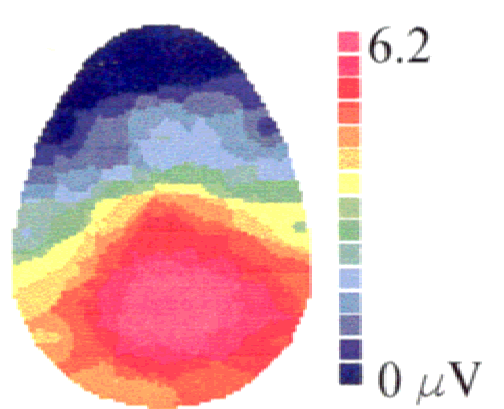

Schizophrenia $(\mathrm{n}=14)$

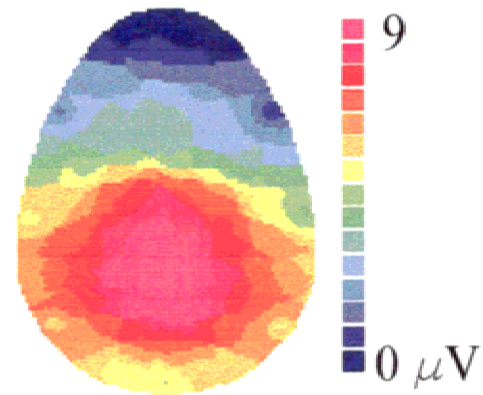

Affective psychosis $(n=14)$

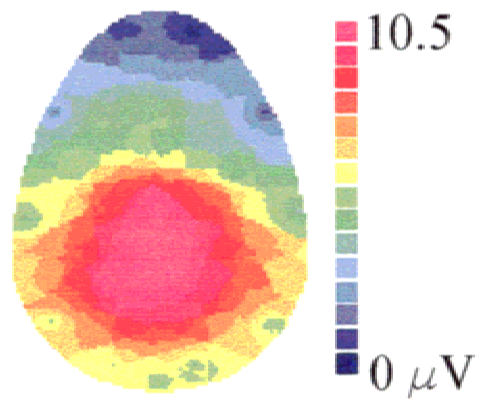

Control $(\mathrm{n}=14)$

Figure 2. The voltage topography of the P300 component to target tones in normal subjects, first-episode patients with affective disorders and psychotic features, and first-episode patients with schizophrenia. Only patients with schizophrenia show a right-shifted P300 topography. Note the use of different microvolt scales for the different groups. 
approach involves use of statistical methods to correlate abnormalities of surface-recorded ERPs with abnormalities in specific cortical structures.

\section{Depth Recording and Lesion Studies of P300 Sources}

Both depth recordings and lesion studies in humans have been used to identify the neural regions involved in the generation of the scalp-recorded P300 component. Depth electrode studies in humans and monkeys have shown in the posterior hippocampus electrical activity that resembles the surface-recorded P300 in its relationship to task demands and stimulus probability (Halgren et al., 1980; McCarthy, Wood, Williamson, Williams, \& Spencer, 1989; Paller, McCarthy, Roessler, Allison, \& Wood, 1992). However, a large scalp-recorded P300 component may persist after extensive damage to the medial temporal lobes (Johnson, 1988; Knight, 1996; Polich \& Squire, 1993; Stapleton \& Halgren, 1987), suggesting that the hippocampus is not the primary scalp P300 generator. Findings of reduced P300 amplitude after medial temporal lobe damage are usually confined to lateral electrode sites in the temporal regions, particularly when the posterior hippocampus is involved (McCarthy, Darcey, Wood, Williamson, \& Spencer, 1987; O’Donnell et al., 1993a; Onofrj et al., 1992). Depth recordings have also shown P300-like activity in the frontal lobe, inferior temporal lobe, superior temporal gyrus, inferior parietal lobe (Halgren et al., 1992; Smith et al., 1990), and the surface of the midtemporal lobe (Neshige \& Luders, 1992). Strokes confined to the superior parietal lobe or frontal lobe in humans have little effect on the scalp-recorded P300 component. Strokes to the superior temporal lobe and adjacent parietal tissue, however, dramatically reduce P300 amplitude on scalp recordings (Knight, Scabini, Woods, \& Clayworth, 1989; Knight, 1990).

In summary, depth recording and lesion studies have most consistently implicated the temporal lobe and inferior parietal lobe structures in the generation of the auditory P300. Recent functional MRI studies using auditory oddball paradigms have also implicated the temporal-parietal cortex. Turetsky, Raz, and Alsop (1998) reported activation in the superior temporal gyrus, and Menon, Ford, Lim, Glover, \& Pfefferbaum (1997) reported activation in the supramarginal gyrus of the parietal lobe.

\section{Bioelectric Modeling of the ERP Using High-Density Recordings and MRI-Derived Finite Element Head Models}

Depth recordings and lesion effects in humans can only be studied in patient populations. Over the past decade, the rapid evolution of quantitative MRI and high-density electroencephalogram (EEG) methods has spurred the development of biophysical techniques that permit noninvasive mapping of scalp-recorded electrical fields to anatomic structures. These techniques are often referred to as electrical source analysis and can be used with healthy subjects of any age. In this section, the biophysical basis of electrical source analysis is reviewed, and an example of an approach using a realistic head model is described.

Synchronized inhibitory and excitatory postsynaptic potentials of large numbers of pyramidal neurons in laminar cortex results in current flows of sufficient magnitude to be conducted through the relative insulator of the skull and measured at the scalp surface (Fender, 1987; Mitzdorf, 1991; Wood \& Allison, 1981). Source analysis attempts to determine the number, strength, orientation, and location of the generating sources in the brain responsible for the EEG data recorded at the scalp surface. Determination of the relationship between recorded EEG and underlying sources is an inverse problem and as such has no unique solution (Scherg, 1990; Vaughan, Ritter, \& Simpson, 1983; Williamson \& Kaufman, 1990). Although source analysis techniques begin with a topographic description of voltage across the scalp, this information is inadequate to make inferences regarding activity at the cortical surface and underlying cortex without precise mapping of the electrode locations on the surface of the head.

The distribution of the electrical field through a volume conductor is described by Poisson's equation (see Johnson, 1994, for a full discussion). If Poisson's equation is replaced by the general Laplacian, in which the electrical field distribution at one surface (e.g., the cortex) is calculated from the distribution at another (e.g., the scalp), then the electrical inverse does have an unique solution, although the problem is still ill-posed in the Hadamard sense, that is, small errors in the input can lead to unbounded errors in the solution (see Johnson, 1994). Accurate description of the scalp field from high-density recordings and accurate modeling using anatomically realistic head models is needed to minimize this input error.

If an ERP recording system has only a few electrodes, then there will be large gaps between the electrodes, and some high spatial frequency characteristics of the ERP may be missed (Srinivasan, Tucker, \& Murias, 1998; Tucker, Liotti, Potts, Russell, \& Posner, 1994; Wikswo, Gevins, \& Williamson, 1993). If the recording electrodes are clustered over a restricted area of the head then an incomplete and spatially biased representation of the electrical field may result (Tucker et al., 1994). Estimates of the interelectrode distance necessary to fully characterize the scalp ERP range from $1 \mathrm{~cm}$ to $2.5 \mathrm{~cm}$ (Gevins, Brickett, Costales, \& Le, 1990; Spitzer, Cohen, Fabrikant, \& Hallett, 1989; Srebro, 1990). A 64channel array provides an interelectrode distance of approximately $3.8 \mathrm{~cm}$ (Tucker, 1993), lower than the estimated spatial Nyquist of high spatial frequency ERP components but superior to the $6-\mathrm{cm}$ interelectrode difference of the standard 10/20 system. A 64channel system may be sufficient to characterize a component with a broad spatial distribution, such as the P300.

Most approaches to the EEG inverse solution include a spherical representation of the head, which does not capture individual differences in head shape, skull thickness, and cortical morphology (Buchner et al., 1995; Roth, Balish, Gorbach, \& Sato, 1993). Several groups have used anatomically accurate head models in inverse solutions (e.g., Buchner et al., 1995; Gevins, Brickett, Reutter, \& Desmond, 1991; Gevins et al., 1994; Lütkenhöner et al., 1995; Roth et al., 1993; Srebro, 1990), but most of these models are limited in the number of tissues represented (e.g., Lütkenhöner et al., 1995, used two: brain and not brain). In collaboration with the Scientific Computing and Imaging group at the University of Utah, we have implemented a scalp surface-cortical surface EEG inverse solver using subject-specific MRI-derived finite element head models with five tissue types: skin, bone, gray matter, white matter, and cerebrospinal fluid (CSF) (SCIrun; Johnson \& Parker, 1995; Weinstein, Johnsen, \& Schmidt, 1995).

In this solver, a subject's grayscale MRI was segmented into the five tissue types using a manually assisted expectation maximization segmenter (Wells, Grimson, Kikinis, \& Jolesz, 1994). A finite element structural head model was created from the segmented MRI. Each element in the model was assigned a conductivity value based upon its tissue type (skin: 1.000; skull: 0.050; CSF: 4.620; gray matter: 1.000; white matter: 0.430; after Peters \& DeMunck, 1991) to create a volume conductor model of the subject's head. For this example, the EEG was acquired using a 64- 
channel recording system (Electrical Geodesics, Eugene, OR). At the EEG collection stage a magnetic digitization system (Polhemus, Colchester, VT) was used to create a digital representation of the subject's head surface and the location of the recording electrodes relative to that head surface. The MRI data were used to create a three-dimensional representation of the head surface from the skin tissue type. The digitized head surface was then aligned with the MRI-reconstructed head surface, coregistering the digitization space with the MRI space and allowing the localization of the ERP recording electrodes relative to the MRI-defined head structure. The distribution of the cortical electrical field was then computed in the volume conductor head model from the 64channel scalp surface recordings.

Figure 3 shows an interpolation of the auditory P300 on a general head model compared to a scalp surface-cortical surface

\section{Subject DS's P300 from 300 to $400 \mathrm{~ms}$ Interpolation and Bioelectric Model}

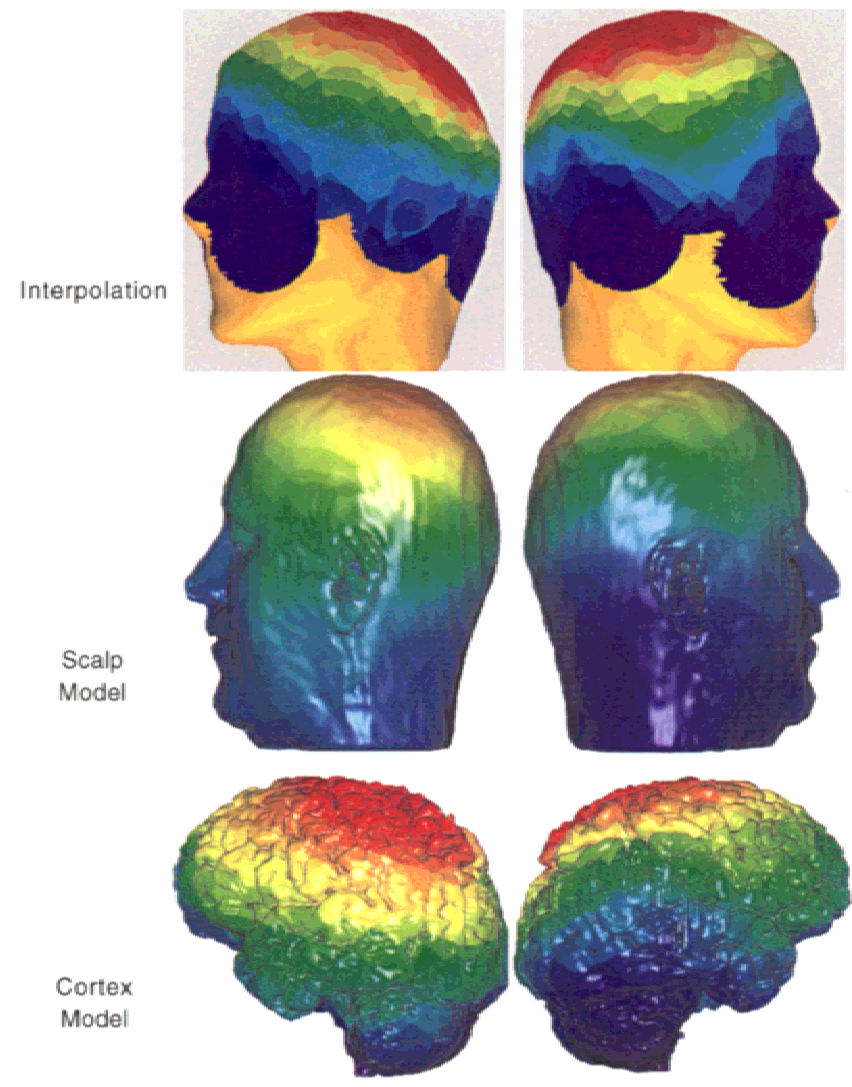

Figure 3. Spline interpolated P300 topography registered with a threedimensional head using the SCIrun finite element modeling system. The top figures show the interpolated P300 distribution on the simulated head, the middle figures show the bioelectric model at the scalp using the subject's own MRI data, and the bottom figure shows the cortical surface model. The field distribution at the cortex more clearly shows the lateralized distribution of the P300 when the smearing effect of the higher resistance skull is removed (bottom). Dorsal positivity appears larger on the left, and ventral negativity appears larger on the right, suggestive of a transverse orientation of at least one of the P300 generators. Over both cortical hemispheres the contour of the field, as shown by color transitions, is parallel to the plane of the posterior superior temporal gyrus, with a sharp voltage gradient near that structure. inverse solution in a subject-specific MRI-derived head model. The P300 component was recorded using an auditory oddball paradigm with silent counting, as described by Potts et al. (1998). The current maxima are broadly mapped over gyri on the superior surface of the brain. Thus, other source analysis techniques such as dipole modeling can be applied on current measures that have been associated with specific cortical surfaces. The P300 component shows a left $>$ right hemispheric asymmetry in the current distribution in a normal adult male subject. The cortical field contours are parallel to the posterior portion of the superior temporal gyrus (STG) and show a steep voltage gradient along this region, consistent with a contribution of the posterior STG to the auditory P300 response in this subject. These findings are consistent with a report by Turetsky et al. (1998) on functional MRI activation during an auditory target task, which showed prominent STG activation and greater activation in the left than in the right side.

\section{Anatomic Correlates of Auditory Oddbal Changes in Schizophrenia}

Although the biophysical technique described above provides a method for describing the electrical field over an individual's cortical surface and is consistent with an STG electrical source, more direct evidence is needed to determine whether P300 amplitude reduction and topographic asymmetries are correlated with structural changes in the temporal lobe in schizophrenia. The STG, the medial temporal lobe, and the inferior parietal lobe have been implicated in the generation of the P300 component. Which of these regions, if any, are associated with P300 amplitude and topographic abnormalities in schizophrenia? Here we describe a series of studies in which the relationship between gray matter volume in specific temporal lobe structures and the scalp-recorded P300 component in schizophrenia was directly examined.

The foundation for our first set of correlational studies consisted of a sample of chronic patients with schizophrenia and severe psychotic symptoms (hallucinations, delusions, or thought disorder) who also were evaluated using quantitative MRI techniques. The use of image processing workstations in conjunction with the MRI data has allowed in vivo studies of neuroanatomy, with precise measurement of the volume and position of neuroanatomic structures. As Vaughan et al. (1983) pointed out, neuroanatomic structures differ markedly between individuals, and this variation necessitates individual measurement as a foundation of correlational studies. These MRI anatomic techniques, like postmortem quantitative neuropathology, require painstaking effort. Once characterized, this structural information can then be used for correlational studies or realistic biophysical modeling of source characteristics.

As reviewed previously, studies of the topography of P300 in schizophrenia have frequently shown that P300 amplitude reduction in schizophrenia is greater at left than at right temporal scalp electrode sites (Bruder et al., 1996; McCarley et al., 1997). Such findings led McCarley et al. (1991) to suggest that left temporal lobe abnormalities may play a major role in schizophrenia, especially in the genesis of positive symptoms. Quantitative MRI analysis by Shenton et al. (1992) showed that a group of schizophrenic patients had reduction of the gray matter volume of the STG and medial temporal lobe structures that was more severe on the left side. By recording auditory ERPs in these same patients, we were able to determine whether P300 amplitude on surface recordings was correlated with volume reductions of neural structures in the temporal lobe, including the STG, posterior hippocampus, anterior 
hippocampus-amygdala, and parahippocampal gyrus. Of these structures, only the volume of the STG correlated with P300 amplitude. Moreover, when correlation coefficients were evaluated along a coronal electrode chain ( $\mathrm{T} 3, \mathrm{C} 3, \mathrm{Cz}, \mathrm{C} 4$, and T4), the correlations were largest proximal to $\mathrm{T} 3$ on the left and smallest on the right side of the head, consistent with left STG modulation of the P300 component recorded in that region (McCarley et al., 1993). This relationship was also consistent with reports by Knight et al. (1989) that strokes involving the temporal-parietal region, particularly on the left side, produced widespread reduction of the auditory P300 component. One way of displaying these data is to generate an interpolated map of the correlations between left posterior STG and P300 amplitude, as shown in Figure 4 (O'Donnell et al., 1993b). This topographic map displays the correlation gradient in two dimensions, with the larger coefficients at left as compared with right temporal sites and larger coefficients at posterior as compared with anterior sites. These data support the idea that the physiological abnormality of P300 amplitude reduction and topographic asymmetry is anatomically associated with left posterior STG volume reduction.

One issue raised by these studies in patients affected by chronic schizophrenia is whether factors such as chronic morbidity, longterm neuroleptic treatment, or other effects associated with chronic mental illness may contribute to the relationship between leftlateralized P300 and STG abnormalities. To determine if temporal lobe P300 and MRI abnormalities are present at the onset of the illness, we evaluated the auditory P300 component and STG volumes in first-episode patients with schizophrenia or affective psychosis and in age-matched controls (Hirayasu et al., 1997; Salisbury et al., 1998). Quantitative MRI evaluation revealed that schizophrenic patients showed significantly reduced gray matter in the left STG compared to first-episode affective psychotic patients or control subjects. Correlational analysis showed that the total gray matter volume of the STG in schizophrenic patients was correlated with P300 amplitude at T3. These data suggest that the relationship between the left STG and P300 abnormalities reported in chronic schizophrenia are present at the onset of the illness.

\section{Correlation of P300 Amplitude and Left Posterior STG Volume}

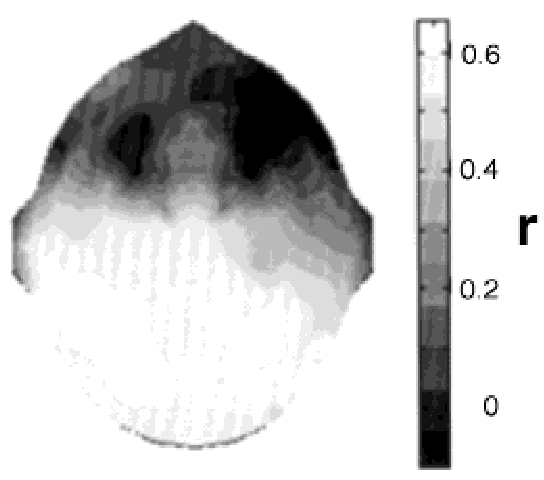

Figure 4. Map of correlation coefficients of P300 voltage recorded at 28 scalp sites with gray matter volume of the left posterior superior temporal gyrus. Note the region of significant correlations in the left posterior temporal region of the scalp.
Partial Least Squares Analysis of Associations Between ERPs and Structural MRI

Partial least squares analysis. Inspection of the topography of correlation coefficients between a neuroanatomic abnormality and ERP voltages over the scalp may provide support for a source model (Figure 4). The above results, although providing evidence of a link between the left posterior STG volume and P300 amplitude in schizophrenia, suffer from the shortcomings of univariate correlational analyses: multiple univariate statistical tests on intercorrelated variables. Relating high-density scalp recordings of ERPs with the results of other brain imaging modalities involves testing the relationship between large numbers of intercorrelated measures from two domains. Because brain imaging studies typically involve small numbers of subjects, traditional methods of identifying relationships among many data measures such as factor analysis and canonical correlation often cannot be applied. In the example used below, for example, the number of variables exceeds the number of subjects, and therefore neither factor analysis nor canonical correlation can be used.

Bookstein and colleagues (Bookstein, Sampson, Streissguth, \& Barr, 1996; McIntosh, Nyberg, Bookstein, \& Tulving, 1997; Streissguth, Bookstein, Sampson, \& Barr, 1993) have developed new statistical methods, collectively referred to as partial least squares (PLS), which can be used to characterize the relationship between two sets of measures. These methods can be applied to large, multicollinear sets of measures in relatively small subject samples. For example, McIntosh, Bookstein, Haxby, and Grady (1996) tested the relationship between a set of measures obtained from brain images (e.g., patterns of activation) and measures indexing experimental demands (e.g., face encoding). In this section, we apply PLS to relate a large block of ERP measures (N200 and P300 amplitude measured across multiple electrode sites) to a block of measures of anatomic regions.

Computationally, PLS carries out a singular value decomposition of a cross-correlation matrix between two blocks of measures. Unlike canonical correlation, which maximizes the correlation between blocks of measures, PLS maximizes the covariance between blocks. The singular value decomposition produces a series of paired singular vectors or latent variables (LV). The number of LVs produced is equal to the number of measures in the block with the fewest dimensions (measures). PLS computes the covariance between pairs of LVs using the statistic $d$, the first singular value of the correlation matrix. The sum of the squared singular values is equal to the sum of the squared elements of the original crosscorrelation matrix. Successive pairs of LVs have the maximum covariance under the constraint that each of the pair is geometrically orthogonal to all LVs extracted previously for its own block. Hence successive pairs of LVs will have smaller covariances (decreasing values of $d$ ). Each LV is paired, so that one member of the pair is composed of saliences (or weights) corresponding to each measure in Block 1 and the other is composed of saliences for each measure in Block 2. Each vector of saliences is exactly proportional to the profile of correlations of the variables of its block, with the LV score corresponding to the other block. Permutation tests, which are based on a distribution generated by randomized groupings of the rows of the original data, are then used to assess statistical significance.

A computational example. O'Donnell et al. (1993b) correlated N200 and P300 amplitude with a set of temporal lobe anatomic structures. Using univariate correlations, they found that P300 am- 
plitude was correlated significantly with gray matter volume of the left posterior STG but not with medial temporal lobe structures in patients with schizophrenia (Figure 4). N200 amplitude, however, was correlated with measures of medial temporal lobe structures as well as the STG, suggesting that the circuits affecting N200 amplitude differed from those affecting P300 amplitude in schizophrenia. PLS thus appears to be a good statistical method to determine how N200 and P300 amplitude measured at multiple electrode sites relate to a set of left and right temporal lobe structures. We therefore carried out PLS analysis on this data set (see O'Donnell et al., 1993b, for the methodology for measuring ERP and MRI variables). The first block for the PLS analysis included N200 and P300 voltages measured at all the electrode sites in the 10-20 system and at Oz. The second block included measures of gray matter volumes obtained for the anterior and posterior temporal gyrus, the parahippocampal gyrus, the amygdala and anterior hippocampus, and the posterior hippocampus. Absolute rather than relative volumes were used in measuring the MRI regions of interest because there is a biophysical relationship between neural tissue volume and the magnitude of the current flow it generates. There were 40 variables in the ERP block and 10 variables in the MRI block.

From the cross-correlation matrix obtained from the P300 and MRI measures, PLS extracted 10 LVs, LV1-LV10. Each LV consisted of two pairs, designated $\mathrm{LV}_{\text {erp }}$ and $L V_{\text {mri }}$. Each pair of LVs was associated with a singular value, $d$. The percentage of the summed squared cross-block correlation accounted for by a particular LV is calculated by dividing the squared singular value of that LV by the sum of the squared singular values produced by the analysis. $\mathrm{LV}_{\text {erp }}$ has a salience or weight for each electrode channel for N200 and P300, and $\mathrm{LV}_{\mathrm{mri}}$ has a salience for each MRI measure. The saliences for LV1 and LV2 are listed in Table 1. The magnitude of the salience indicates the contribution of that measure to the LV pair with which it is associated. ERP saliences are listed from anterior to posterior sites to assist in topographic interpretation.

In interpreting the relationship between the block of ERP measures and the block of MRI measures, we first examine the magnitude of $d$ and then the saliences for each variable on LV1. For LV1, $d=5.47$ and $d^{2}=29.92$. Because the sum of the squared singular values for the $10 \mathrm{LVs}$ in the solution was 42.53, the percentage of the summed squared cross-block correlation accounted for by LV1 is $29.92 / 42.53 \times 100$, or $70.4 \%$. Permutation tests revealed a significant relationship between the two blocks of measures for LV1 $(p<.03)$. We therefore conclude that there is a significant relationship between ERP amplitude recorded at these sites and the block of temporal lobe measures. By inspecting the magnitude of the saliences for each pair of LV1, the contribution of each measure to this relationship can be evaluated (Table 1). For $\mathrm{LV} 1_{\mathrm{erp}}$, all but four of the saliences for N200 amplitude exceeded .20, whereas none of the saliences for P300 measures exceeded an absolute value of .20. LV1 $1_{\text {erp }}$, then, appeared to be strongly related to $\mathrm{N} 200$ amplitude. For $\mathrm{LV} 1_{\text {mri }}$, the saliences on left anterior STG, left and right posterior STG, left and right parahippocampal gyrus, left amygdala, and right posterior hippocampus are less than -.20 . Only one structure, right amygdalaanterior hippocampus has a positive weight greater than .20 . These findings suggest that N200 amplitude is related to the gray matter volumes of a large set of temporal lobe structures, particularly to left STG, the parahippocampal gyri, and the left and right amygdala. The relationship of $L V 1_{\text {erp }}$ and $L V 1_{\text {mri }}$ can be graphically displayed by plotting individual scores for each subject on $L V 1_{\text {erp }}$ and $L V 1_{\text {mri }}$. The score of a subject on one of the LV pairs is
Table 1. Saliences for Latent Variable Pairs 1 and 2

\begin{tabular}{|c|c|c|c|c|c|}
\hline $\begin{array}{l}\text { ERP } \\
\text { Amplitude } \\
\text { Measures }\end{array}$ & $L V 1_{\text {erp }}$ & $\mathrm{LV} 2_{\text {erp }}$ & $\begin{array}{l}\text { MRI Volume } \\
\text { Measures }\end{array}$ & $\mathrm{LV} 1_{\mathrm{mri}}$ & $\mathrm{LV} 2_{\mathrm{mri}}$ \\
\hline \multicolumn{6}{|l|}{ P300 } \\
\hline Fp1 & .007 & -.020 & Left posterior STG & -.368 & -.664 \\
\hline Fp2 & .112 & .018 & Left anterior STG & -.374 & .227 \\
\hline $\mathrm{Fz}$ & .050 & -.104 & Right posterior STG & -.223 & -.278 \\
\hline F3 & .033 & -.108 & Right anterior STG & -.018 & .019 \\
\hline F4 & .138 & -.076 & Left parahippocampus & -.339 & .319 \\
\hline F7 & .048 & .022 & Right parahippocampus & -.470 & .068 \\
\hline F8 & .005 & .050 & Left amygdala/ant hipp & -.372 & .466 \\
\hline $\mathrm{Cz}$ & -.039 & -.188 & Right amygdala/ant hipp & .226 & .286 \\
\hline $\mathrm{C} 3$ & -.058 & -.198 & Left post hippocampus & .132 & .154 \\
\hline $\mathrm{C} 4$ & .000 & -.168 & Right post hippocampus & -.364 & -.019 \\
\hline T3 & -.083 & -.213 & & & \\
\hline $\mathrm{T} 4$ & -.078 & -.098 & & & \\
\hline $\mathrm{Pz}$ & -.031 & -.279 & & & \\
\hline P3 & -.058 & -.293 & & & \\
\hline P4 & -.049 & -.284 & & & \\
\hline T5 & -.055 & -.303 & & & \\
\hline T6 & -.042 & -.269 & & & \\
\hline O1 & -.041 & -.321 & & & \\
\hline $\mathrm{O} 2$ & -.019 & -.331 & & & \\
\hline $\mathrm{Oz}$ & -.040 & -.326 & & & \\
\hline \multicolumn{6}{|l|}{ N200 } \\
\hline Fp1 & .047 & -.041 & & & \\
\hline $\mathrm{Fp} 2$ & .052 & -.045 & & & \\
\hline $\mathrm{Fz}$ & .245 & .035 & & & \\
\hline F3 & .222 & .052 & & & \\
\hline $\mathrm{F} 4$ & .237 & .016 & & & \\
\hline F7 & .091 & .059 & & & \\
\hline F8 & -.069 & .057 & & & \\
\hline $\mathrm{Cz}$ & .229 & -.019 & & & \\
\hline C3 & .236 & .016 & & & \\
\hline $\mathrm{C} 4$ & .241 & .028 & & & \\
\hline T3 & .239 & .030 & & & \\
\hline $\mathrm{T} 4$ & .202 & -.014 & & & \\
\hline $\mathrm{Pz}$ & .244 & -.110 & & & \\
\hline P3 & .259 & -.055 & & & \\
\hline P4 & .248 & -.056 & & & \\
\hline T5 & .276 & -.047 & & & \\
\hline T6 & .244 & -.043 & & & \\
\hline $\mathrm{O} 1$ & .245 & -.123 & & & \\
\hline $\mathrm{O} 2$ & .228 & -.104 & & & \\
\hline $\mathrm{Oz}$ & .213 & -.129 & & & \\
\hline
\end{tabular}

Note: $\mathrm{STG}=$ superior temporal gyrus; ant $=$ anterior; hipp $=$ hippocampus.

calculated by multiplying each raw score by its corresponding salience and then summing the products. For example, to obtain the score of the first subject for $L V 1_{\text {erp }}$, the values of $\mathrm{N} 200$ and P300 for each channel would be multiplied by their saliences, and the sum of these products would yield the $L V 1_{\text {erp }}$ score. Figure 5 shows the scattergram for $\mathrm{LV} 1_{\text {erp }}$ and $\mathrm{LV} 1_{\text {mri }}$ for the 15 subjects. The Pearson correlation coefficient for these values was .79 $(p<$ .01). In general, larger temporal lobe MRI volumes yielded a more negative $\mathrm{LV} 1_{\text {mri }}$ score, and more negative $\mathrm{LV} 1_{\text {mri }}$ scores are associated with more negative $\mathrm{LV} 1_{\text {erp }}$ scores.

LV1, then, related N200 amplitude to the block of MRI structures. LV2, in contrast, related P300 amplitude to the MRI measures. $L V 2_{\text {erp }}$ shows a pattern of saliences that is complementary to

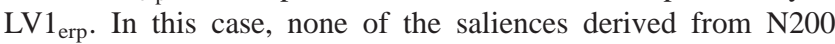
measures has an absolute value greater than .20. P300 had saliences more negative than -.20 on sites T3, T5, T6, P3, P4, Pz, O1, 
Latent Variable 1 (N200)

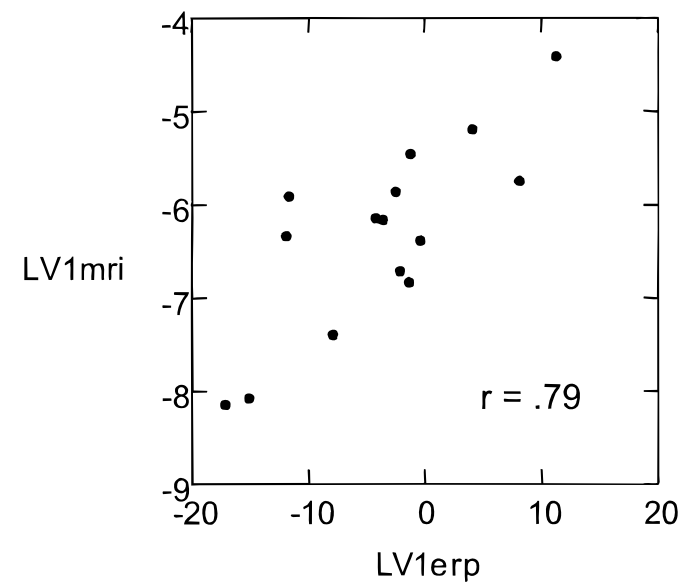

Latent Variable 2 (P300)

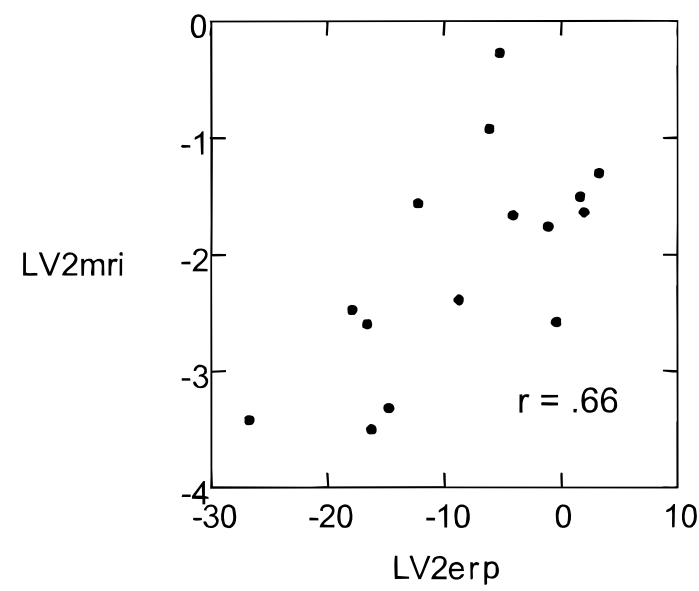

Figure 5. Scattergrams showing the relationship of ERP and MRI measures used in the partial least squares analysis for the latent variables, LV1 and LV2. For each latent variable, a subject had a score computed from the sum of the products of saliences and raw values on the ERP or MRI variable set. Plots of these scores show the nature and strength of the relationship for the N200 component (left scattergram) and the P300 component (right scattergram).

$\mathrm{Oz}$, and $\mathrm{O} 2 . \mathrm{LV} 2_{\text {erp }}$, then, appeared to be highly influenced by P300 voltages at posterior sites, with T3 showing a greater salience than T4 as in the original correlational analysis (McCarley et al., 1993). Because the saliences for $P 300$ voltage were negative, positive P300 voltages produced a more negative score on LV2 erp. The saliences for the $\mathrm{LV} 2_{\text {mri }}$ present a more complex picture. Larger values for the left and right posterior STG move $\mathrm{LV} 2_{\text {mri }}$ in a negative direction because the saliences for these measures were negative. The saliences for left anterior STG, left parahippocampus, and left and right amygdala were positive, and larger MRI raw scores on these measures move $\mathrm{LV} 2_{\mathrm{mri}}$ in a positive direction. The scattergram of individual scores on $\mathrm{LV} 2_{\text {erp }}$ and $\mathrm{LV} 2_{\text {mri }}$ is shown in Figure 5. The correlation between LV $2_{\text {erp }}$ and LV $2_{\text {mri }}$ was .66 ( $p<$ $.05)$. Given the relationship of saliences to raw scores described previously, larger positive values for the posterior STG, particularly on the left side, were associated with larger P300 voltage values. In contrast, larger values on left anterior STG and several medial temporal lobe structures are associated with smaller raw P300 voltage values.

LV2 has a $d^{2}$ value of 6.55 and accounted for $15.4 \%$ of the summed squared cross-block correlation for the analysis. We have not yet completed a satisfactory approach to testing the significance of LV2, although a separate PLS using only P300 amplitude measures showed a significant relationship between P300 and left posterior STG $(p<.05)$. In combination, LV1 and LV2 account for $85 \%$ of the summed squared cross-block correlation. Because LV1 and LV2 have zero covariance, these results also indicate that N200 and P300 amplitude, although affected by many of the same experimental factors such as stimulus probability and target value, can be statistically distinguished on the basis of their anatomic correlates. We will not attempt an interpretation of the remaining eight LVs, which account for the remaining $15 \%$ of the summed squared cross-block correlation.

\section{Discussion}

Interpretation of the pathophysiological significance of ERP abnormalities hinges on identifying which neural circuits are in- volved in the generation of a specific component. A variety of approaches have been applied to answering the structural question of the relationship of scalp-recorded ERPs and specific regions of the brain. No single approach can unambiguously specify this relationship. Depth-recorded activity in a region, for example, may not be conducted to the scalp. Lesions may disrupt any of a number of steps in the neural generation of a component without necessarily affecting the critical cognitive apparatus. In a radio receiver analogy, lesions may affect the power supply or the speaker without affecting the tuner; thus, it is useful to have multiple sites with lesions so that, if possible, a double dissociation may be produced. Dipole methods may produce simple models that correlate well with scalp topography but are implausibly situated in the brain. Other modalities of brain imaging, such a regional cerebral blood flow, may be sensitive to slow changes in the brain and insensitive to the highly transient activity indexed by ERPs. Consequently, a multimethod strategy is required to approximate an answer to this question, particularly for components that index cognitive processes.

As an example of a multimethod strategy, we examined the auditory P300 component and its relationship to temporal lobe structures in schizophrenia. Several lines of evidence are consistent with a major role of the STG and adjacent inferior parietal lobe tissue as a source of the scalp-recorded P300 component, including depth recordings (Halgren et al., 1995a, 1995b), neurologic lesion evidence (Knight, 1996; Knight et al., 1989), and functional MRI activation (Menon et al., 1997; Turetsky et al., 1998). We focused on temporal lobe structures because of consistent anatomic evidence of abnormalities in these structures in schizophrenia (McCarley et al., in press; Shenton et al., 1997). Bioelectric modeling and a new multivariate technique, PLS analysis, were used to examine the relationship of the P300 component to underlying cortical structures measured by quantitative MRI. In conjunction, these findings suggest that temporal lobe structures, especially the STG, contribute to the scalp-recorded ERP component. In the multivariate PLS analysis, left temporal P300 amplitude reduction was associated with volume reduction in posterior STG, especially on the left side, but was not associated with MRI volume reduction in medial temporal lobe structures. Al- 
though N200 was also reduced in schizophrenia, it was much more strongly associated with abnormalities of medial temporal lobe structures than was the P300. Although other brain regions undoubtedly contribute to the P300 component (Halgren et al., 1995a, 1995b), these findings provide a foundation for the understanding of pathophysiological changes in schizophrenia (McCarley et al., 1997), a disorder frequently associated with structural abnormalities of the temporal lobe and functional abnormalities of auditory and language processing (Hirayasu et al., 1997;
McCarley et al., 1996; Shenton et al., 1997). Our analyses have not included all brain regions potentially involved in P300 production, but the methodology outlined here may be used to incorporate such data as they become available. We expect that the combination of surface-recorded ERP data with data from structural MRI, depth recordings, and other functional brain image modalities will greatly accelerate progress in the identification of neural circuits underlying other ERP components in both normal and clinical populations.

\section{REFERENCES}

Benes, F. M. (1995). Is there a neuroanatomic basis for schizophrenia? An old question revisited. The Neuroscientist, 1, 104-115.

Benes, F. M., \& Bird, E. D. (1987). An analysis of the arrangement of neurons in the cingulate cortex of schizophrenic patients. Archives of General Psychiatry, 44, 608-616.

Blackwood, D. H. R., Whalley, L. J., Christie, J. E., Blackburn, I. M., St. Clair, D. M., \& McInnes, A. (1987). Changes in auditory P3 eventrelated potential in schizophrenia and depression. British Journal of Psychiatry, 150, 154-160.

Bleuler, E. (1950). Dementia praecox or the group of schizophrenias. New York: International Universities Press. (Original work published in 1911)

Bolsche, F., MacCrimmon, D. J., \& Kropf, S. (1996). The effect of laterality of stimulus presentation on auditory P300 topography in schizophrenia. Journal of Psychiatric Neuroscience, 21(2), 83-88.

Bookstein, F. L., Sampson, P. D., Streissguth, A. P., \& Barr, H.M. (1996). Exploiting redundant measurement of dose and developmental outcome: New methods from the behavioral teratology of alcohol. Developmental Psychology, 32, 404-415.

Bruder, G. E., Tenke, C. E., Rabinowicz, E., Towey, J. P., Malaspina, D., Amador, X., Kaufmann, C. A., \& Gordon, J. M. (1996). Electrophysiologic studies of brain activity in schizophrenia. In C. A. Kaufman \& J. M. Gorman (Eds.), Schizophrenia: New directions for clinical research and treatment (pp. 17-33). Larchmont, NY: Marianne Leibert.

Buchner, H., Waberski, T. D., Fuchs, M., Wischmann, H.-A., Wagner, M., \& Drenckhahn, R. (1995). Comparison of realistically shaped boundaryelement and spherical head models in source localization of early somatosensory evoked potentials. Brain Topography, 8(2), 137-143.

Chapman, L. J., \& Chapman, J. P. (1973). Selection of subjects in studies of schizophrenic cognition. Journal of Abnormal Psychology, 86, 10-15.

Faux, S. F., McCarley, R. W., Nestor, P. G., Shenton, M. E., Pollak, S. D., Penhune, V., Mondrow, E., Marcy, B., Peterson, A., Horvath, T., \& Davis, K. L. (1993). P300 topographic asymmetries are present in unmedicated schizophrenics, Electroencephalography and Clinical Neurophysiology, 88, 32-41.

Faux, S. F., Shenton, M. E., McCarley, R. W., Nestor, P. G., Marcy, B., \& Ludwig, A. (1990). Preservation of P300 event-related potential topographic asymmetries in schizophrenia with use of either linked-ear or nose reference sites. Electroencephalography and Clinical Neurophysiology, 75, 378-391.

Fender, D. H. (1987). Source localization of brain electrical activity. In A.S. Gevins \& A. Remond (Eds.), Methods of analysis of brain electrical and magnetic signals: EEG handbook (rev. series, Vol. 1, pp. 355403). New York: Elsevier.

Ford, J. M., White, P. M., Csernanasky, J. G., Faustman, W. O., Roth, W. T., \& Pfefferbaum, A. (1994a). ERPs in schizophrenia: Effects of antipsychotic medication. Biological Psychiatry, 36, 153-170.

Ford, J. M., White, P. M., Lim, K. O., \& Pfefferbaum, A. (1994b). Schizophrenics have fewer and smaller P300s: A single-trial analysis. Biological Psychiatry, 35, 96-103.

Ford, M. R., \& Sidman, R. D. (1988, July). Resting and P300 auditory responses in normal subjects and psychiatric patients. Paper presented at the 12th International Association for Mathematics and Computers in Simulation, Paris.

Gerez, M., \& Tello, A. (1995). Selected Quantitative EEG (QEEG) and event-related potential (ERP) variables as discriminators for positive and negative schizophrenia. Biological Psychiatry, 38, 34-39.

Gevins, A., Brickett, P., Costales, B., \& Le, J. (1990). Beyond topographic mapping: Towards functional-anatomical imaging with 124-channel EEGs and 3-D MRIs. Brain Topography, 3, 53-64.
Gevins, A., Le, J., Brickett, P., Reutter, B., \& Desmond, J. (1991). Seeing through the skull: Advanced EEGs use MRIs to accurately measure cortical activity from the scalp. Brain Topography, 4, 125-131.

Gevins, A., Le, J., Martin, N. K., Brickett, P., Desmond, J., \& Reutter, B. (1994). High resolution EEG: 124-channel recording, spatial deblurring and MRI integration methods. Electroencephalography and Clinical Neurophysiology, 90, 337-358.

Grillon, C., Ameli, R., \& Glazer, W. M. (1991). N400 and semantic categorization in schizophrenia. Biological Psychology, 29, 467-480.

Grillon, C., Courchesne, E., Ameli, R., Geyer, M. A., \& Braff, D. L. (1990). Increased distractibility in schizophrenic patients. Archives of General Psychiatry, 47, 171-179.

Halgren, E., Baudena, P., Clarke, J.M., Heit, G., Liegeois, C., Shauvel, P., \& Musolino, A. (1995a). Intracerebral potentials to rare target and distracter auditory and visual stimuli: I. Superior temporal plane and parietal lobe. Electroencephalography and Clinical Neurophysiology, 94, 191-220.

Halgren, E., Baudena, P., Clarke, J. M., Heit, G., Marinkovik, K., Devaux, B., Vignal, J. P., \& Biraben, A. (1995b). Intracerebral potentials to rare target and distracter auditory and visual stimuli: II. Medial lateral and posterior temporal lobe. Electroencephalography and Clinical Neurophysiology, 94, 229-250.

Halgren, E., Baudena, P., Heit, G., Chauvel, P., Musolino, A., Devaux, B. Clarke, J., Scarbin, J.-M., \& Vignal, J.-P. (1992, June). Endogenous potentials in the human superior temporal sulcus by rare and repeated stimuli. Paper presented at the 10th International Congress of Evoked Potentials, Eger, Hungary.

Halgren, E. G., Squires, N. K., Wilson, C. L., Rohrbaugh, J. W., Babb, T. L., \& Campbell, P. H. (1980). Endogenous potentials generated in the human hippocampal formation and the amygdala by infrequent events. Science, 210, 803-805.

Hirayasu, Y., Asato, N., Ohta, H., Hokama, H., Arakaki, H., \& Ogura, C. (1998). Abnormalities of auditory event-related potentials prior to treatment. Biological Psychiatry, 43, 244-253.

Hirayasu, Y., Shenton, M. E., Salisbury, D. F., Fisher, I. A., Dickey, C. C., Kisler, T., Arakaki, H., Yurgelin-Todd, D. A., Tohen, M., \& McCarley, R. W. (1997). MRI and ERP abnormalities in first episode psychosis. Biological Psychiatry, 41, 60S.

Johnson, C. R., \& Parker, S. G. (1995). Applications in computational medicine using SCIRun: A computational steering programming environment. In Supercomputer '95 (pp. 2-19). New York: Springer-Verlag.

Johnson, J. R. (1994). Numerical models for bioelectric field problems. In J. D. Bronzino (Ed.), Biomedical engineering handbook (pp. 161-188). Boca Raton, FL: CRC Press.

Johnson, R. J. (1988). Scalp-recorded P300 activity in patients following unilateral temporal lobectomy. Brain, 111, 1517-1529.

Knight, R. T. (1990). Neural mechanisms of event-related potentials: Evidence from human lesion studies. In J. Rohrbaugh, R. Parasuraman, \& R. Johnson, Jr. (Eds.), Event-related brain potentials: Basic issues and applications (pp. 3-18). New York: Oxford University Press.

Knight, R. T. (1996). Contribution of human hippocampal region to novelty detection. Nature, 383, 256-259.

Knight, R. T., Scabini, D., Woods, D. L., \& Clayworth, C. C. (1989). Contributions of temporal-parietal junction to the human auditory P3. Brain Research, 502, 109-116.

Kovelman, J. A., \& Scheibel, A. B. (1984). A neurohistological correlate of schizophrenia. Biological Psychiatry, 191, 1601-1621.

Kraepelin, E. (1971). Dementia praecox (E. Barclay and S. Barclay, Trans.). New York: Churchill Livingstone. (Original work published in 1919)

Kraft, L. W., Schwartzskopf, S. B., Torello, M. W., Olsen, S. C., \& Nas- 
rallah, H. A. (1991). Auditory P300 changes and third ventricle enlargement in outpatient schizophrenics. Biological Psychiatry, 29, 163A.

Levit, R. A., Sutton, S., \& Zubin, J. (1973). Evoked potential correlates of information processing in psychiatric patients. Psychological Medicine, 3, 487-494.

Lütkenhöner, B., Menninghous, E., Steinsträter, O., Wienbruch, C., Gibler, H. M., \& Elbert, T. (1995). Neuromagnetic source analysis using magnetic resonance images for the construction of source and volume conductor model. Brain Topography, 7, 291-299.

McCarley, R. W., Faux, S. F., Shenton, M. E., Nestor, P. G., \& Adams, J. (1991). Event-related potentials in schizophrenia: Their biological and clinical correlates and a new model of schizophrenic pathophysiology. Schizophrenia Research, 4, 209-223.

McCarley, R. W., Hsiao, J., Freedman, R., Pfefferbaum, A., \& Donchin, E. (1996). Neuroimaging and the cognitive neuroscience of schizophrenia. Schizophrenia Bulletin, 22, 703-725.

McCarley, R. W., O’Donnell, B. F., Niznikiewicz, M. A., Salisbury, D. F., Potts, G. F., Hirayasu, Y., Nestor, P. G., \& Shenton, M. E. (1997). Update on electrophysiology. International Review of Psychiatry, 9, 373-386.

McCarley, R. W., Shenton, M. E., O’Donnell, B. F., Faux, S. F., Kikinis, R., Nestor, P. G., \& Jolesz, F. A. (1993). Auditory P300 abnormalities and left posterior superior temporal gyrus volume reduction in schizophrenia. Archives of General Psychiatry, 50, 190-197.

McCarley, R. W., Wible, C., Frumin, M., Hirayasu, Y., Levitt, J. J., Fischer, I., \& Shenton, M. E. (in press). MRI anatomy of schizophrenia. Biological Psychiatry.

McCarthy, G., Darcey, C. C., Wood, P. D., Williamson, P. D., \& Spencer, D. D. (1987). Asymmetries in scalp and intracranial endogenous ERPs in patients with complex partial epilepsy. In J. Engel, G. A. Ojemann, H. O. Luders, \& P. D. Williamson (Eds.), Fundamental mechanisms of human brain function (pp. 51-59). New York: Raven Press.

McCarthy, G., Wood, C. C., Williamson, P. D., Williams, P. D., \& Spencer, D. D. (1989). Task-dependent field potentials in human hippocampal formation. Journal of Neuroscience, 18, 4523-4268.

McIntosh, A. R., Bookstein, F. L., Haxby, J., \& Grady, C. L. (1996). Spatial pattern analysis of functional brain images using partial least squares. Neuroimage, 3, 143-157.

McIntosh, A. R., Nyberg, L., Bookstein, F., \& Tulving, E. (1997). Differential connectivity of prefrontal and medial temporal cortices during episodic memory retrieval. Human Brain Mapping, 5, 323-327.

Menon, V., Ford, J. M., Lim, K. O., Glover, G. H., \& Pfefferbaum, A. (1997). Combined event-related and EEG evidence for temporalparietal cortex activation during target detection. Neuroreport, 8, 30293037.

Mitzdorf, U. (1991). Physiological sources of evoked potentials. Electroencephalography and Clinical Neurophysiology Supplement, 42, 47-57.

Morstyn, R., Duffy, F. H., \& McCarley, R. W. (1983). Altered P300 topography in schizophrenia. Archives of General Psychiatry, 62, 203208.

Muir, W. J., St. Clair, D., \& Blackwood, D. H. (1991). Long-latency auditory event-related potentials in schizophrenia and in bipolar and unipolar affective disorder. Psychologie Medicale, 21, 867-879.

Neale, J. M., \& Oltmanns, T. F. (1980). Schizophrenia. New York: Wiley \& Sons.

Neshige, R., \& Luders, H. (1992). Recording of event-related potentials (P300) from human cortex. Journal of Clinical Neurophysiology, 9, 294-298.

Nestor, P. G., \& O'Donnell, B. F. (1997). The mind adrift: Attention dysregulation in schizophrenia. In $\mathrm{R}$. Parasuraman (Ed.), The attentive brain (pp. 527-546). Boston: MIT Press.

O’Donnell, B. F., Cohen, R. A., Hokama, H., Cuffin, B. N., Lippa, C., Drachman, D. A., \& Shenton, M. E. (1993a). Electrical source analysis of auditory ERP abnormalities in medial temporal lobe post-encephalitic amnestic syndrome. Electroencephalography and Clinical Neurophysiology, 87, 394-402.

O’Donnell, B. F., Ohta, H., McCarley, R. W., Hokama, H., Wible, C. G., Law, S., Nestor, P. G., Kikinis, R., Jolesz, F. A., \& Shenton, M. E. (1996). The auditory P3a and P3b ERP components in schizophrenia: Relationship to frontal and temporal lobe MRI volumes. In C. Ogura, Y. Koga, \& M. Shimokochi (Eds.), Proceedings of the XIth International Conference on Event-Related Potentials of the Brain. (pp. 30-35). New York: Elsevier.

O’Donnell, B. F., Shenton, M. E., McCarley, R. W., Faux, S. F., Smith, R. S., Salisbury, D. F., Nestor, P. G., Pollak S. D., Kikinis, R., \& Jolesz,
F. A. (1993b). The auditory N200 component in schizophrenia: Relationship to MRI temporal lobe grey matter and to other ERP abnormalities. Biological Psychiatry, 34, 26-40.

Olney, J. W., \& Farber, N. B. (1995). Glutamate receptor dysfunction and schizophrenia. Archives of General Psychiatry, 52, 998-1007.

Onofrj, M., Fulgente, T., Nobilio, D., Malatesta, G., Bazzano, S., Colmartino, P., \& Gambi, D. (1992). P3 recordings in patients with bilateral temporal lobe lesions. Neurology, 42, 1762-1767.

Paller, K. A., McCarthy, G., Roessler, E., Allison, T., \& Wood, C. C. (1992). Potentials evoked in human and monkey medial temporal lobe during auditory and visual oddball paradigms. Electroencephalography and Clinical Neurophysiology, 84, 269-79.

Patterson, B. W., Williams, H. L., McLean, G. A., Smith, T. L., \& Scaeffer, K. W. (1987). Alcoholism and family history of alcoholism: Effects on visual and auditory event-related potentials. Alcohol, 4, 265-274.

Peters, M. J., \& DeMunck, J. C. (1991). The influence of model parameters on the inverse solution based on MEGS and EEGs. Acta Otolaryngologica Supplement, 419, 91-99.

Pfefferbaum, A., Ford, J. M., White, P. M., \& Mathalon, D. (1991). Eventrelated potentials in alcoholic men: P3 amplitude reflects family history but not alcohol consumption. Alcoholism: Clinical and Experimental Research, 15, 839-850.

Pfefferbaum, A., Ford, J. M., White, P. M., \& Roth, W. T. (1989). P3 in schizophrenia is affected by stimulus modality, response requirements, medication status, and negative symptoms. Archives of General Psychiatry, 46, 1035-1044.

Pfefferbaum, A., Wenegrat, B. G., Ford, J. M., Roth, W. T., \& Kopell, B. S. (1984). Clinical application of the P3 component of the event-related potentials: II. Dementia, depression and schizophrenia. Electroencephalography and Clinical Neurophysiology, 59, 104-124.

Polich, J., \& Squire, L. R. (1993). P300 from amnesic patients with bilateral hippocampal lesions. Electroencephalography and Clinical Neurophysiology, 86, 408-417.

Potts, G. F., Hirayasu, Y., O’Donnell, B. F., Shenton, M.E., \& McCarley, R.W. (1998). High density recording and topographic analysis of the auditory oddball event-related potential in patients with schizophrenia. Biological Psychiatry, 42, 982-989.

Roth, B. J., Balish, M., Gorbach, A., \& Sato, S. (1993). How well does a three-sphere model predict positions of dipoles in a realistically shaped head? Electroencephalography and Clinical Neurophysiology, 87, 175184.

Roth, W. T., Duncan, C. C., Pfefferbaum, A., \& Timsit-Berthier, B. M. (1986). Applications of cognitive ERPs in psychiatric patients. Electroencephalography and Clinical Neurophysiology Supplement, 38, 419438.

Roth, W. T., Pfefferbaum, A., Horvath, T. B., Berger, P. A., \& Kopell, B. (1980). P3 reduction in auditory evoked potentials of schizophrenics. Electroencephalography and Clinical Neurophysiology, 49, 497-505.

Salisbury, D. F., O'Donnell, B. F., McCarley, R. W., Nestor, P. G., Faux, S. F., \& Smith, R. S. (1994). Parametric manipulations of auditory stimuli differentially affect P3 amplitude in schizophrenics and controls. Psychophysiology, 31, 29-36.

Salisbury, D. F., Shenton, M. E., Sherwood, A. R., Fischer, I., YurgelunTodd, D. A., Tohen, M., \& McCarley, R. W. (1998). First-episode schizophrenic psychosis differs from first-episode affective psychosis and controls in P300 amplitude over left temporal lobe. Archives of General Psychiatry, 55, 173-180.

Salisbury, D. F., Voglmaier, M. M., Seidman, L. J., \& McCarley, R. W. (1996). Topographic abnormalities of P3 in schizotypal personality disorder. Biological Psychiatry, 40, 165-172.

Scherg, M. (1990). Fundamentals of dipole source analysis. Advances in Audiology, 6, 40-69.

Scherg, M., \& Berg, P. (1996). New concepts of brain source imaging and localization. Electroencephalography and Clinical Neurophysiology Supplement, 46, 127-137.

Shenton, M. E., Kikinis, R., Jolesz, F. A., Pollak, S. D., LeMay, M., Wible, C. G., Hokama, H., Martin, J., Coleman, M., Metcalf, D., \& McCarley, R. W. (1992). Abnormality of the left temporal lobe and thought disorder in schizophrenia. A quantitative magnetic resonance imaging study. New England Journal of Medicine, 327, 604-612.

Shenton, M. E., Wible, C. G., \& McCarley, R. W. (1997). A review of magnetic resonance imaging studies of brain abnormalities in schizophrenia. In K. R. Krishnan \& P. M. Doraiswamy (Eds.), Brain imaging in clinical psychiatry (pp. 297-379). New York: Marcel Dekker. 
Sieg, K. G., Willsie, D. A., Preston, D. F., \& Gaffney, G. R. (1991). Brain imaging: Evoked potential, quantitative EEG and SPECT abnormalities in schizophrenia. Journal of Psychiatry Neuroscience, 16, 41-44.

Smith, M. E., Halgren, E., Sokolik, M., Baudena, P., Musolino, A., Liegeois, C. C., \& Chauvel, P. (1990). The intracranial topography of the P3 event-related potential elicited during auditory oddball. Electroencephalography and Clinical Neurophysiology, 76, 235-248.

Souza, V. B. N., Muir, W. J., Walker, M. T., Glabus, M. F., Roxborough, H. M., Sharp, C. W., Dunan, J. R., \& Blackwood, D. H. R. (1995) Auditory P300 event-related potentials and neuropsychological performance in schizophrenia and bipolar affective disorder. Biological Psychiatry, 37, 300-310.

Spitzer, A. R., Cohen, L. G., Fabrikant, J., \& Hallett, M. A. (1989). A method for determining optimal interelectrode spacing for cerebral topographic mapping. Electroencephalography and Clinical Neurophysiology, 72, 355-361.

Srebro, R. (1990). Realistic modeling of VEP topography. Vision Research, 30, 1001-1009.

Srinivasan, R., Tucker, D. M., \& Murias, M. (1998). Estimates of the spatial Nyquist of the human EEG. Behavioral Research Methods, Instruments, \& Computers, 30, 8-19.

Stapleton, J. M., \& Halgren, E. (1987). Endogenous potentials evoked in simple cognitive tasks: Depth components and task correlates. Electroencephalography and Clinical Neurophysiology, 67, 44-52.

Streissguth, A. P., Bookstein, F. L., Sampson, P. D., \& Barr, H. M. (1993). The enduring effects of prenatal alcohol exposure on child development. Ann Arbor: University of Michigan Press.

Strik, W. K., Dierks, T., Franzek, E., Stober, G., \& Maurer, K. (1994a). P300 asymmetries in schizophrenia revisited with reference-independent methods. Psychiatry Research, 55, 153-166.

Strik, W. K., Dierks, T., Franzek, E., Stober, G., \& Maurer, K. (1994b). P300 in schizophrenia: Interactions between amplitudes and topography. Biological Psychiatry, 35, 850-856.

Tucker, D. M. (1993). Spatial sampling of head electrical fields: The geodesic sensor net. Electroencephalography and Clinical Neurophysiology, 87, 154-163.

Tucker, D. M., Liotti, M., Potts, G. F., Russell, G. S., \& Posner, M. I. (1994). Spatiotemporal analysis of brain electrical fields. Human Brain Mapping, 1, 134-152.
Turesky, B. I., Raz, J., \& Alsop, D. (1998, July). Functional magnetic resonance imaging of the sources of the auditory P300. Paper presented at the $12^{\text {th }}$ International Congress of Evoked Potentials, Boston.

Turetsky, D. I., Colbath, E. A., Erwin, R. J., \& Gur, R.E. (1998). Subcomponent abnormalities in schizophrenia: Effects of gender and clinical subtype. Biological Psychiatry, 43, 84-96.

Vaughan, H. G., Ritter, W., \& Simpson, R. (1983). Neurophysiological considerations in event-related potential research. In W.K. Gaillard \& W. Ritter (Eds.), Tutorials in event-related potential research: Endogenous components (pp. 1-7). Amsterdam: Elsevier.

Weinstein, D. M., Johnson, C. R., \& Schmidt, J. A. (1995, July). Effects of adaptive refinement on the inverse EEG solution. Paper presented at the International Society for Optical Engineering Annual Meeting, San Diego.

Weisbrod, M., Winkler, S., Maier, S., Hill, H., Thomas, C., \& Spitzer, M. (1997). Left lateralized P300 amplitude deficit in schizophrenic patients depends on pitch disparity. Biological Psychiatry, 41, 541-549.

Wells, W. M., III, Grimson, W. E. L., Kikinis, R., \& Jolesz, F. A. (1994) Statistical intensity correction and segmentation of MRI data. SPIE: Visualization in Biomedical Computing, 2359, 13-24.

Wible, C. G., Shenton, M. E., \& McCarley, R. W. (1997). Neuroanatomy of the limbic system and the planum temporale. In K. R. R. Krishnan \& P. M. Doraiswamy (Eds.), Brain imaging in clinical psychiatry (pp. 63-101). New York: Marcel Dekker.

Wikswo, J. P. J., Gevins, A., \& Williamson, S. J. (1993). The future of the EEG and MEG. Electroencephalography and Clinical Neurophysiology, 87, 1-9.

Williamson, S., \& Kaufman, L. (1990). Theory of neuroelectric and neuromagnetic fields. In F. Grandori, M. Hoke, \& G. Romani (Eds.), Auditory evoked magnetic fields and electric potentials (pp. 1-39). Basel: Karger.

Wood, C. C., \& Allison, T. (1981). Interpretation of evoked potentials: A neurophysiological perspective. Canadian Journal of Psychology, 35, $113-135$.

(RECEIVED November 5, 1997; ACCEPTED November 7, 1998) 